\title{
Genótipos de feijoeiro comum sob deficiência hídrica
}

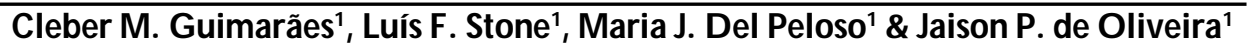

\section{RESU MO}

O bjetivou-se com este trabalho estudar a adaptação de genótipos de feijoeiro comum à deficiência hídrica. Avaliaram-se 49 genótipos no delineamento de blocos ao acaso, com três repetições, em experimentos com e sem deficiência hídrica, na Estação Experimental da SEAGRO, em Porangatu, GO , em 2006 e 2007. Aplicou-se a análise multivariada através do método de $W$ ard e se classificaram os genótipos em quatro grupos, considerando-se os valores médios das produtividades observadas em cada ambiente hídrico, nos dois anos de condução dos experimentos. Verificou-se que as produtividades médias dos grupos diferiram significativamente entre si tanto no ambiente com como naquele sem deficiência hídrica. Os genótipos BRA 130583 CIAT G 6490 e FT 84 - 292 foram classificados como mais produtivos tanto na ausência como na presença de deficiência hídrica enquanto os genótipos BRA 283983 CIAT G 6492, BRA 129721 CIAT G 6896 e G 983 foram classificados como produtivos na ausência de deficiência hídrica porém foram mais sensíveis a esse estresse. Verificou-se, dentre os componentes primários da produção do feijoeiro comum, que o número de vagens por planta foi 0 componente agronômico mais sensível à deficiência hídrica.

Palavras-chave: Phaseolus vulgaris, componentes da produtividade, temperatura das folhas, tolerância à deficiência hídrica

\section{Common bean genotypes under water stress}

\begin{abstract}
The objective of the work was to study the adaptation of common bean genotypes to water deficit. Fortynine genotypes were evaluated in a randomized block design, with three replications, in experiments with and without water deficit, conducted at the Experimental Station of SEAGRO, in Porangatu-GO during 2006 and 2007. Multivariable analysis was applied using de W ard's method and the genotypes were divided in four groups based on the average grain yield of each water treatment, during the two years of the experimentation. The genotypes BRA 130583 CIAT G 6490 and FT 84 - 292 were classified as the most productive in the absence or under water deficit, while the genotypes BRA 283983 CIAT G 6492, BRA 129721 CIAT G 6896, and G 983 were classified as productive in the absence of water deficit, but they were more sensitive to this stress. It was also verified that the number of pods per plant was the most sensitive agronomic component to water deficit in common bean.
\end{abstract}

Key words: Phaseolus vulgaris, yield components, leaf temperature, water stress 


\section{INTRODUÇÃO}

A adaptação de plantas a ambientes de estresse é um desafio da agricultura moderna, fato que torna necessário se entender o seu comportamento em ambientes contrastantes, com e sem estresse, e a inter-relação entre eles (Lizana et al., 2006). Entre o vários estresses abióticos, a deficiência hídrica se destaca pela amplitude de ocorrência e pela redução na produtividade (Muñoz-Perea et al., 2006). Estima-se que 60\% da produção mundial de feijão vêm de regiões com deficiência hídrica, o que a torna a segunda maior causa de redução da produtividade da cultura (Singh, 1995). O efeito da deficiência hídrica no feijoeiro comum só não é maior em virtude do seu curto ciclo de desenvolvimento, que não vai além dos 80-90 dias, evitando os períodos mais intensos de falta de chuvas que ocorrem no fim do período chuvoso (Steinmetz et al., 1988). No Brasil, o feijoeiro comum (Phaseolus vulgaris L.) é cultivado em praticamente todo o território nacional, em várias épocas de semeadura, o que o expõe a uma grande diversidade climática (Didonet, 2005). A deficiência hídrica é mais importante pela intermitência das chuvas do que pela quantidade precipitada, principalmente em uma das regiões mais produtoras, a dos Cerrados. Nesta região chove no período compreendido entre os meses de outubro a abril; todavia, a partir do mês de janeiro podem ocorrer períodos de deficiência hídrica (Steinmetz et al., 1988), que comprometem a produtividade da cultura, pelos estresses hídricos induzidos à planta em seus diferentes períodos de desenvolvimento.

A adaptação à deficiência hídrica decorre, dentre outros fatores, da manutenção de boa condição hídrica nos tecidos das plantas (Kramer \& Boyer, 1995), avaliada pelo potencial da água na planta, pela resistência difusiva estomática e pela temperatura do dossel (Bascur et al., 1985; Hsiao, 1990; Pimentel \& Perez, 2000). Guimarães \& Zimmermann (1985) observaram que os genótipos de feijoeiro comum mais tolerantes à deficiência hídrica apresentaram potenciais da água na folha mais altos e sistemas radiculares mais desenvolvidos no perfil do solo, de 20 a $60 \mathrm{~cm}$ de profundidade, em comparação com o mais sensível. Corroborando com esta informação, CIAT (1985) e White \& Sponchiado (1985) concluíram que os genótipos de feijoeiro comum mais tolerantes à deficiência hídrica mantiveram potenciais da água na folha mais altos e resistências estomáticas mais baixas, por apresentaram sistemas radiculares mais profundos que os dos mais suscetíveis. Pimentel \& Perez (2000) constataram que o potencial da água na folha é um excelente indicador do efeito da deficiência hídrica no feijoeiro comum e, aliado à área foliar e à massa da matéria seca da parte aérea, pode caracterizar genótipos mais tolerantes a esse estresse. Por sua vez, White \& Castillo (1989) constataram que o crescimento do dossel da planta é de menor importância que o sistema radicular na determinação da tolerância à deficiência hídrica de genótipos de feijoeiro comum. Guimarães et al. (1996), em concordância com as observações anteriores, verificaram que o genótipo BAT 477 e cultivar Carioca, mais tolerantes a esse estresse apresentaram, nos tratamentos com deficiência hídrica e em relação ao irrigado, maior densidade e eficiência radicular na absorção de água, nas camadas mais profundas, do que o genótipo RAB 96 mais sensível. Essas características proporcionaram, à cultivar Carioca e também ao genótipo BAT 477, menor redução da área foliar e menor aumento da massa específica foliar, que significa manutenção da área de síntese de carboidratos e melhor fluxo deles aos sítios de armazenamento resultando, finalmente, em maior produtividade dos genótipos mais adaptados à deficiência hídrica.

Objetivou-se, com este trabalho, estudar a adaptação de genótipos de feijoeiro comum à deficiência hídrica, como suporte a programas de melhoramento que visam à criação de cultivares para regiões sujeitas a esse estresse abiótico.

\section{MATERIAL E MÉTODOS}

Os experimentos foram conduzidos em solo classificado como Latossolo Vermelho distrófico, na Estação Experimental da EMATER, em Porangatu, GO, localizada a $13^{\circ} 18^{\prime} 31^{\prime \prime}$ de latitude Sul e 49 06' 47" de longitude Oeste, com altitude de 391 m e clima Aw, tropical de savana, megatérmico, segundo a classificação de Köppen. Durante o período de condução do experimento não ocorreram chuvas e os dados da umidade relativa média diária e das temperaturas máximas e mínimas são apresentados na Figura 1.
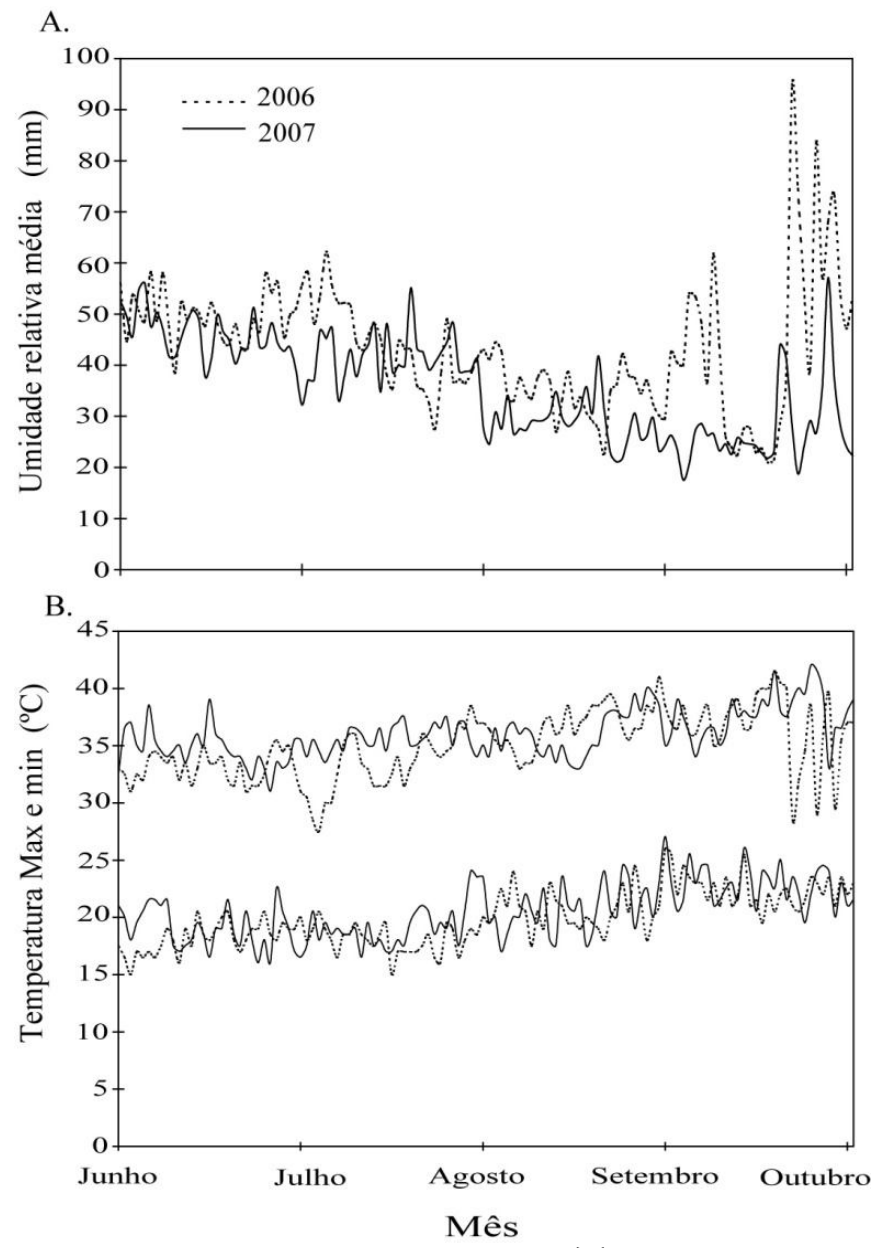

Figura 1. U midade relativa média $(A)$ e temperaturas máxima e mínima $(B)$ durante o período de condução dos experimentos, em 2006 e 2007, na Estação Experimental da EM ATER, Porangatu, GO 
As semeaduras foram efetuadas em 11/06/2006 e 14/06/2007, em parcelas de quatro fileiras, com quatro metros de comprimento e espaçadas $50 \mathrm{~cm}$. A densidade de semeadura foi de 18 sementes por metro. A demanda das plantas por nitrogênio, fósforo e potássio foi suprida com a aplicação de 16, 120 e $64 \mathrm{~kg} \mathrm{ha}^{-1} \mathrm{de} \mathrm{N}$, $\mathrm{P}_{2} \mathrm{O}_{5}$ e $\mathrm{K}_{2} \mathrm{O}$, respectivamente, mediante a fórmula comercial 4-3016. A adubação de cobertura foi efetuada com $30 \mathrm{~kg} \mathrm{ha}^{-1}$ de N, aos 20 dias após a emergência, na forma de sulfato de amônio. $\mathrm{O}$ controle de plantas daninhas foi efetuado com $250 \mathrm{~g} \mathrm{ha}^{-1} \mathrm{de}$ fomesafen e $187 \mathrm{~g} \mathrm{ha}^{-1}$ de fluazifop-p-butyl, aos três dias após a emergência. Adotou-se o delineamento em blocos casualizados com três repetições, em dois experimentos, com e sem deficiência hídrica, nos dois anos de condução do trabalho. O primeiro experimento recebeu condição adequada de água no solo - 0,035 MPa a $15 \mathrm{~cm}$ de profundidade (Silveira \& Stone, 1994), durante todo o desenvolvimento das plantas e o outro apenas até os 20 dias após a emergência, quando foi aplicada a deficiência hídrica. As irrigações no experimento irrigado adequadamente e durante a fase sem deficiência hídrica do segundo experimento, foram controladas com tensiômetros, ou seja, foram efetuadas novas irrigações de aproximadamente $25 \mathrm{~mm}$ quando o potencial da água no solo, a $15 \mathrm{~cm}$ de profundidade, atingiu - 0,035 MPa. Durante o período de deficiência hídrica aplicou-se aproximadamente metade da lâmina de água usada no experimento sem deficiência hídrica. Avaliaram-se a produtividade, a massa de 100 grãos, o número de grãos vagem ${ }^{-1}$, o número de vagens planta ${ }^{-1}$, o número de plantas $\mathrm{m}^{-2} \mathrm{e}$ o número de dias até a floração das plantas, pelos métodos convencionais, e a temperatura das folhas conforme Guimarães et al. (2006).

Os dados obtidos foram submetidos à análise de variância, considerando-se os dois anos experimentais, e as médias o foram à análise de regressão. Agruparam-se os acessos por meio de análise multivariada de acordo com o método de Ward (1963).

\section{RESULTADOS E DISCUSSÃO}

Os genótipos foram classificados em quatro grupos, considerando-se os valores médios das produtividades observadas em cada ambiente hídrico, nos dois anos de condução dos experimentos (Tabelas 1 e 2). Verificou-se que as produtividades médias dos grupos diferiram significativamente entre si tanto no ambiente com deficiência hídrica como naquele com irrigação adequada (Tabela 3).

As produtividades médias dos dois anos de condução dos experimentos foram de 863 e $2084 \mathrm{~kg} \mathrm{ha}^{-1}$, com e sem deficiência hídrica, respectivamente. Portanto, os genótipos sofreram uma redução média de 58,6\% da produtividade devido à deficiência hídrica (Tabelas 1 e 2). Conforme Jongdee et al. (2006), para as condições de deficiência hídrica moderada, quando a produtividade é reduzida em menos de $50 \%$ o potencial de produtividade dos genótipos é um importante mecanismo de seleção. Mecanismos de escape e de tolerância são demandados para deficiências hídricas mais severas.

Verificou-se que sob condições de deficiência hídrica o grupo menos produtivo (G4) foi composto dos genótipos, $\mathrm{G}$ 3566, BRA 283983 CIAT G 6492, BAT 1203, Brasil 0001, RAB 94
Vermelho 2157, G 983 e BRA 129721 CIAT G 6896, que produziram em média $657 \mathrm{~kg} \mathrm{ha}^{-1}$. Sob essas mesmas condições, o grupo mais produtivo (G1) se compôs dos genótipos Bambuí, FT 84 - 292, G 4280, BAT 304 e BRA 130583 CIAT G 6490, que produziram em média $1080 \mathrm{~kg} \mathrm{ha}^{-1}, 64,4 \%$ superior à do grupo anterior. Sob condições hídricas adequadas o grupo menos produtivo (G4) foi composto dos genótipos, BAT 1203, EMP 86, Piratã 1, G2475, Brasil 0001, FE 732007 - Xamego, G 4489, FFT 85 - 75 - Porto Real e G 2359, que produziram em média 1754 $\mathrm{kg} \mathrm{ha}^{-1}$. Sob essas mesmas condições o grupo mais produtivo (G1) foi composto dos genótipos BRA 130583 CIAT G 6490, FT 84-292, G 4825, G 20716, IPA 7, G 2358, G 13571, BRA 283983 CIAT G 6492, FT 85 - 79, G 1356 e IAC UNA, que produziram em média $2429 \mathrm{~kg} \mathrm{ha}^{-1}, 38,5 \%$ superior à do grupo menos produtivo.

Para atender às condições climáticas de deficiência hídrica das regiões produtoras com disponibilidade irregular de chuvas, como a dos Cerrados, a tolerância a esse estresse deve ser uma característica agregada das cultivares desde que, na maioria das vezes, ocorre boa disponibilidade de chuva. Neste sentido, deve-se considerar, na seleção, a produtividade em condições adequadas de irrigação e com deficiência hídrica.

Conforme Jongdee et al. (2006), cultivares com boa produtividade podem ser desenvolvidas em condições de deficiência hídrica e, ao mesmo tempo, responder bem às condições favoráveis de umidade do solo, desde que sejam avaliadas em ambos os ambientes. Esta afirmativa, segundo os autores, é viável para as deficiências hídricas moderadas. Rosielle \& Hamblin (1981) também afirmaram que os genótipos devem somar tolerância à deficiência hídrica e potencial produtivo e, ainda, que a seleção baseada somente na produtividade sob deficiência hídrica severa pode produzir genótipos pouco produtivos em ambiente sem deficiência hídrica. Já Schneider et al. (1997) acrescentam que a estratégia mais efetiva para o aumento da tolerância à deficiência hídrica envolve uma seleção baseada na média geométrica dos dois regimes hídricos, seguida de uma segunda, baseada na produtividade sob deficiência hídrica.

Selecionaram-se, portanto, dois genótipos, BRA 130583 CIAT G 6490 e FT 84 - 292, classificados no grupo mais produtivo (G1) dos tratamentos com e sem deficiência hídrica, em que o primeiro produziu 1068 e $2530 \mathrm{~kg} \mathrm{ha}^{-1}$, respectivamente, nos dois tratamentos enquanto o segundo produziu $1091 \mathrm{e}$ $2542 \mathrm{~kg} \mathrm{ha}^{-1}$ nesses mesmos tratamentos hídricos. Os genótipos Bambuí e G 4280 mantiveram o comportamento produtivo sob deficiência hídrica, dos genótipos anteriores, e também foram classificados no grupo mais produtivo (G1); entretanto, produziram significativamente menos sob condições hídricas adequadas e foram classificados no segundo grupo mais produtivo (G2). O genótipo BAT 304 também manteve comportamento produtivo sob deficiência hídrica dos genótipos anteriores por ter sido classificado no grupo mais produtivo (G1); entretanto, produziu sob condições hídricas adequadas, menos que os genótipos Bambuí e G 4280, e foi classificado no grupo G3 (Tabelas 1 e 2).

Os genótipos BRA 283983 CIAT G 6492, BRA 129721 CIAT G 6896 e G 983 foram classificados produtivos quando irrigados adequadamente; entretanto, apresentaram alta sensibilidade à deficiência hídrica. O primeiro genótipo foi classificado nos 
Tabela 1. Produtividade, massa 100 grãos (M S100), número de grãos por vagem (G Vag), número de vagens por planta (VagPI), número de plantas $\mathrm{m}^{-2}$ (Plm${ }^{-2}$ ) e floração (Flor) dos agrupamentos de genótipos de feijoeiro segundo o método de W ard, considerando-se o componente produtividade em condições de deficiência hídrica ${ }^{1}$

\begin{tabular}{|c|c|c|c|c|c|c|c|c|c|c|}
\hline \multirow{2}{*}{ Grupo } & \multirow{2}{*}{ Genótipo } & \multicolumn{4}{|c|}{ Produtividade $\left(\mathrm{kg} \mathrm{ha}^{-1}\right)$} & \multirow{2}{*}{$\begin{array}{c}\text { MS100 } \\
\text { (g) }\end{array}$} & \multirow{2}{*}{$\begin{array}{l}\text { GVag } \\
\text { (nㅇ) }\end{array}$} & \multirow{2}{*}{$\begin{array}{c}\text { VagPI } \\
(\mathrm{n} \div)\end{array}$} & \multirow{2}{*}{$\begin{array}{l}\mathrm{Plm}^{-2} \\
(\mathrm{n}-)\end{array}$} & \multirow{2}{*}{$\begin{array}{l}\text { Flor } \\
\text { (das) }^{2}\end{array}$} \\
\hline & & Média geral & Média grupo & Ano 1 & Ano 2 & & & & & \\
\hline $\mathrm{Gl}$ & $\begin{array}{l}\text { Bambui } \\
\text { FT } 84-292 \\
\text { G } 4280 \\
\text { BAT } 304 \\
\text { BRA } 130583 \text { CIAT G } 6490\end{array}$ & $\begin{array}{l}1113 \\
1091 \\
1091 \\
1038 \\
1068 \\
\end{array}$ & $1080 a$ & $\begin{array}{l}1354 \\
1333 \\
1541 \\
1280 \\
1688 \\
\end{array}$ & $\begin{array}{l}872 \\
848 \\
640 \\
796 \\
448 \\
\end{array}$ & $\begin{array}{l}21,26 \\
18,56 \\
21,25 \\
17,98 \\
18,60 \\
\end{array}$ & $\begin{array}{l}4,4 \\
4,2 \\
4,5 \\
4,4 \\
4,2 \\
\end{array}$ & $\begin{array}{l}7,1 \\
8,3 \\
6,9 \\
8,3 \\
6,3 \\
\end{array}$ & $\begin{array}{l}20,2 \\
20,0 \\
21,7 \\
19,3 \\
19,2 \\
\end{array}$ & $\begin{array}{l}39 \\
41 \\
39 \\
38 \\
44 \\
\end{array}$ \\
\hline G2 & $\begin{array}{l}\text { G } 13571 \\
\text { IPA } 7 \\
\text { BRS MG Talisma - CII } 102 \\
\text { IAC UNA } \\
\text { G } 2475 \\
\text { G } 4825 \\
\text { Coco Blanchi } \\
\text { MA } 534620 \text { - Novo Jalo } \\
\text { G } 1356 \\
\text { BRA } 284297 \text { CIAT G } 18649 \\
\text { G } 4489 \\
\text { BRS Pontal } \\
\text { ESAL } 589 \text { Carioca MG } \\
\text { FE } 732007 \text { - Xamego } \\
\text { Gordo } \\
\text { Rico V. de Minas Gerais } \\
\text { G } 20716\end{array}$ & $\begin{array}{r}998 \\
1001 \\
1011 \\
988 \\
990 \\
975 \\
974 \\
967 \\
944 \\
943 \\
943 \\
954 \\
951 \\
951 \\
905 \\
907 \\
911 \\
\end{array}$ & $960 \mathrm{~b}$ & $\begin{array}{l}1247 \\
1234 \\
1538 \\
1229 \\
1408 \\
1127 \\
1437 \\
1330 \\
1166 \\
1296 \\
1361 \\
1260 \\
1250 \\
1245 \\
1202 \\
1301 \\
1309 \\
\end{array}$ & $\begin{array}{l}749 \\
768 \\
485 \\
747 \\
571 \\
824 \\
511 \\
604 \\
722 \\
591 \\
524 \\
649 \\
652 \\
657 \\
609 \\
514 \\
513 \\
\end{array}$ & $\begin{array}{l}18,63 \\
19,47 \\
23,42 \\
18,42 \\
18,72 \\
20,58 \\
19,66 \\
29,12 \\
17,62 \\
18,16 \\
17,63 \\
19,78 \\
18,48 \\
16,15 \\
29,90 \\
15,52 \\
20,37 \\
\end{array}$ & $\begin{array}{l}4,5 \\
4,1 \\
3,6 \\
3,4 \\
4,3 \\
4,2 \\
4,6 \\
3,0 \\
4,4 \\
3,4 \\
4,4 \\
4,7 \\
5,0 \\
4,7 \\
5,1 \\
4,5 \\
3,9 \\
\end{array}$ & $\begin{array}{r}6,4 \\
9,2 \\
7,6 \\
6,3 \\
5,2 \\
6,7 \\
6,0 \\
5,8 \\
10,1 \\
8,6 \\
5,6 \\
4,9 \\
7,5 \\
8,4 \\
7,9 \\
8,5 \\
8,9 \\
\end{array}$ & $\begin{array}{l}20,0 \\
18,1 \\
17,6 \\
21,2 \\
22,8 \\
18,8 \\
23,8 \\
18,9 \\
17,4 \\
18,9 \\
20,4 \\
19,6 \\
18,3 \\
17,7 \\
17,5 \\
18,1 \\
18,3 \\
\end{array}$ & $\begin{array}{l}40 \\
44 \\
40 \\
39 \\
42 \\
41 \\
44 \\
38 \\
44 \\
50 \\
40 \\
40 \\
43 \\
40 \\
37 \\
44 \\
39 \\
\end{array}$ \\
\hline G3 & $\begin{array}{l}\text { A } 78 \\
\text { G } 14378 \\
\text { SEA } 9 \\
\text { G } 2358 \\
\text { IAPAR } 65 \\
\text { BRS Marfim } \\
\text { EMP } 86 \\
\text { BRA } 283291 \text { CIAT G } 18574 \\
\text { FFT } 85 \text { - } 75 \text { - Porto Real } \\
\text { CARIOCA } \\
\text { PRETO COMUM } \\
\text { SEA } 7 \\
\text { IPA } 11 \text { - Brigida } \\
\text { APORÉ } \\
\text { PIRATÃ } 1 \\
\text { FT } 85 \text { - } 79 \\
\text { G } 2359 \\
\text { G } 3217 \\
\text { G } 3474 \\
\text { G } 2227\end{array}$ & $\begin{array}{l}764 \\
763 \\
760 \\
755 \\
778 \\
771 \\
750 \\
745 \\
729 \\
809 \\
817 \\
820 \\
827 \\
830 \\
832 \\
795 \\
846 \\
851 \\
866 \\
861\end{array}$ & $798 \mathrm{c}$ & $\begin{array}{r}1061 \\
1043 \\
828 \\
1007 \\
962 \\
1197 \\
926 \\
1142 \\
1092 \\
1045 \\
1082 \\
1146 \\
855 \\
1204 \\
877 \\
1153 \\
1130 \\
1162 \\
1074 \\
1363 \\
\end{array}$ & $\begin{array}{l}466 \\
482 \\
691 \\
504 \\
595 \\
345 \\
574 \\
348 \\
365 \\
573 \\
553 \\
494 \\
798 \\
455 \\
788 \\
436 \\
562 \\
539 \\
658 \\
359 \\
\end{array}$ & $\begin{array}{l}19,81 \\
16,99 \\
23,61 \\
18,10 \\
19,18 \\
20,76 \\
15,44 \\
16,82 \\
21,27 \\
20,12 \\
20,45 \\
23,20 \\
16,04 \\
23,83 \\
20,57 \\
19,11 \\
17,30 \\
17,59 \\
15,83 \\
22,80\end{array}$ & $\begin{array}{l}3,7 \\
3,9 \\
3,7 \\
4,4 \\
3,3 \\
3,5 \\
4,2 \\
5,1 \\
3,5 \\
3,6 \\
4,8 \\
3,8 \\
4,9 \\
4,0 \\
4,0 \\
3,7 \\
4,2 \\
4,1 \\
4,1 \\
3,4\end{array}$ & $\begin{array}{l}7,0 \\
8,2 \\
8,0 \\
7,7 \\
6,7 \\
6,2 \\
6,0 \\
4,9 \\
6,8 \\
7,7 \\
5,2 \\
6,3 \\
7,6 \\
4,7 \\
8,0 \\
5,9 \\
7,9 \\
7,0 \\
8,5 \\
6,4\end{array}$ & $\begin{array}{l}17,4 \\
18,3 \\
14,9 \\
14,6 \\
21,8 \\
23,2 \\
21,0 \\
18,2 \\
15,2 \\
20,1 \\
18,3 \\
17,3 \\
19,4 \\
16,4 \\
16,9 \\
17,8 \\
20,3 \\
23,3 \\
21,8 \\
17,8\end{array}$ & $\begin{array}{l}40 \\
45 \\
40 \\
43 \\
41 \\
39 \\
42 \\
45 \\
41 \\
42 \\
49 \\
39 \\
43 \\
43 \\
45 \\
45 \\
43 \\
43 \\
42 \\
42\end{array}$ \\
\hline G4 & $\begin{array}{l}\text { G } 3566 \\
\text { BRA } 283983 \text { CIAT G } 6492 \\
\text { BAT } 1203 \\
\text { Brasil } 0001 \\
\text { RAB } 94 \text { Vermelho } 2157 \\
\text { G } 983 \\
\text { BRA } 129721 \text { CIAT G } 6896\end{array}$ & $\begin{array}{l}658 \\
654 \\
650 \\
645 \\
622 \\
696 \\
676 \\
\end{array}$ & $657 d$ & $\begin{array}{r}784 \\
1088 \\
912 \\
994 \\
810 \\
1244 \\
970 \\
\end{array}$ & $\begin{array}{l}531 \\
219 \\
388 \\
295 \\
435 \\
148 \\
382 \\
\end{array}$ & $\begin{array}{l}16,21 \\
19,32 \\
20,64 \\
18,85 \\
16,45 \\
22,14 \\
20,24 \\
\end{array}$ & $\begin{array}{l}4,0 \\
3,6 \\
4,3 \\
3,9 \\
4,3 \\
3,8 \\
3,3\end{array}$ & $\begin{array}{l}5,5 \\
4,7 \\
4,4 \\
4,3 \\
6,0 \\
5,7 \\
5,1\end{array}$ & $\begin{array}{l}21,7 \\
18,9 \\
16,3 \\
21,2 \\
22,5 \\
17,5 \\
19,5\end{array}$ & $\begin{array}{l}41 \\
39 \\
42 \\
44 \\
40 \\
45 \\
42\end{array}$ \\
\hline & Médias & 863 & & 1169 & 557 & 19,63 & 4,1 & 6,8 & 19,2 & 42 \\
\hline
\end{tabular}

${ }^{1}$ Médias seguidas de mesma letra na coluna não diferem significativamente entre si (teste t $5 \%$ )

${ }^{2}$ das - dias após a semeadura

grupos G4 e G1, com e sem deficiência hídrica, respectivamente, e os dois genótipos seguintes, BRA 129721 CIAT G 6896 e G 983, foram classificados nos grupos G4 e G2, com e sem deficiência hídrica, respectivamente.

$O$ efeito da deficiência hídrica sobre o aumento da precocidade dos genótipos foi pouco expressivo, pois a floração ocorreu, em média, aos 42 dias após a semeadura em ambos os tratamentos hídricos (Tabelas 1 e 2). Não se observou correlação entre a produtividade e a data de floração, nos dois tratamentos hídricos $(\mathrm{r}=-0,171, \mathrm{p} \leq 0,240$ e $\mathrm{r}=-0,055, \mathrm{p} \leq 0,707$, com e sem deficiência hídrica, respectivamente). Ramirez-Vallejo \& Kelly (1998) observaram prolongamento da data de floração e correlação negativa entre a data de enchimento de grãos e a maturação com a produtividade, constatando que o feijoeiro 
Tabela 2. Produtividade, massa 100 grãos (M S100), número de grãos por vagem (G Vag), número de vagens por planta (VagPI), número de plantas $\mathrm{m}^{-2}$ (PIm ${ }^{-2}$ ) e floração (Flor) dos agrupamentos de genótipos de feijoeiro segundo o método de W ard, considerando-se o componente produtividade em condições sem deficiência hídrica ${ }^{1}$

\begin{tabular}{|c|c|c|c|c|c|c|c|c|c|c|}
\hline \multirow{2}{*}{ Grupo } & \multirow{2}{*}{ Genótipo } & \multicolumn{4}{|c|}{ Produtividade $\left(\mathrm{kg} \mathrm{ha}^{-1}\right)$} & \multirow{2}{*}{$\begin{array}{c}\text { MS100 } \\
\text { (g) }\end{array}$} & \multirow{2}{*}{$\begin{array}{l}\text { GVag } \\
\text { (no) }\end{array}$} & \multirow{2}{*}{$\begin{array}{l}\text { VagPI } \\
(\mathrm{n}=)\end{array}$} & \multirow{2}{*}{$\begin{array}{l}\mathrm{Plm}^{-2} \\
(\mathrm{n} \mathrm{0})\end{array}$} & \multirow{2}{*}{$\begin{array}{c}\text { Flor } \\
\text { (das) }\end{array}$} \\
\hline & & Média geral & Média grupo & Ano 1 & Ano 2 & & & & & \\
\hline $\mathrm{G} 1$ & $\begin{array}{l}\text { BRA } 130583 \text { CIAT G } 6490 \\
\text { FT } 84-292 \\
\text { G } 4825 \\
\text { G } 20716 \\
\text { IPA } 7 \\
\text { G } 2358 \\
\text { G } 13571 \\
\text { BRA } 283983 \text { CIAT G } 6492 \\
\text { FT } 85-79 \\
\text { G } 1356 \\
\text { IAC UNA }\end{array}$ & $\begin{array}{l}2530 \\
2542 \\
2565 \\
2380 \\
2352 \\
2303 \\
2327 \\
2432 \\
2400 \\
2411 \\
2479 \\
\end{array}$ & $2429 a$ & $\begin{array}{l}1895 \\
1869 \\
2223 \\
1870 \\
1554 \\
1637 \\
2149 \\
1737 \\
1747 \\
1537 \\
1685 \\
\end{array}$ & $\begin{array}{l}3166 \\
3216 \\
2907 \\
2890 \\
3151 \\
2969 \\
2504 \\
3127 \\
3053 \\
3284 \\
3272 \\
\end{array}$ & $\begin{array}{l}23,49 \\
21,06 \\
24,71 \\
25,02 \\
21,85 \\
20,27 \\
22,69 \\
23,88 \\
24,50 \\
19,41 \\
21,71 \\
\end{array}$ & $\begin{array}{l}5,2 \\
6,3 \\
6,3 \\
5,7 \\
5,7 \\
5,1 \\
6,2 \\
5,6 \\
5,7 \\
6,8 \\
5,1\end{array}$ & $\begin{array}{r}6,7 \\
14,3 \\
11,4 \\
9,2 \\
11,3 \\
15,1 \\
11,4 \\
8,7 \\
12,1 \\
12,2 \\
10,3 \\
\end{array}$ & $\begin{array}{l}23,0 \\
19,2 \\
20,8 \\
18,9 \\
16,8 \\
15,9 \\
18,8 \\
22,1 \\
17,7 \\
18,7 \\
20,8 \\
\end{array}$ & $\begin{array}{l}44 \\
43 \\
42 \\
40 \\
45 \\
43 \\
41 \\
42 \\
44 \\
43 \\
41 \\
\end{array}$ \\
\hline $\mathrm{G} 2$ & $\begin{array}{l}\text { A } 78 \\
\text { G } 4280 \\
\text { BRS MG Talisma - CII } 102 \\
\text { IPA } 11 \text { - Brigida } \\
\text { APORÉ } \\
\text { Bambui } \\
\text { G } 3217 \\
\text { BRS Pontal } \\
\text { BRA } 129721 \text { CIAT G } 6896 \\
\text { ESAL } 589 \text { Carioca MG } \\
\text { G } 983 \\
\text { IAPAR } 65 \\
\text { BRS MARFIM }\end{array}$ & $\begin{array}{l}2200 \\
2203 \\
2191 \\
2195 \\
2196 \\
2236 \\
2229 \\
2169 \\
2152 \\
2123 \\
2115 \\
2113 \\
2108\end{array}$ & $2172 b$ & $\begin{array}{l}1823 \\
1762 \\
1708 \\
1731 \\
1933 \\
1972 \\
1296 \\
1819 \\
1897 \\
1617 \\
1993 \\
1162 \\
1342\end{array}$ & $\begin{array}{l}2578 \\
2644 \\
2675 \\
2658 \\
2459 \\
2501 \\
3163 \\
2519 \\
2406 \\
2630 \\
2237 \\
3065 \\
2874\end{array}$ & $\begin{array}{l}22,86 \\
22,52 \\
23,31 \\
19,61 \\
24,06 \\
24,83 \\
21,15 \\
24,36 \\
22,73 \\
20,87 \\
23,86 \\
21,68 \\
24,64\end{array}$ & $\begin{array}{l}5,0 \\
5,7 \\
5,6 \\
5,9 \\
6,6 \\
5,3 \\
6,7 \\
6,8 \\
5,1 \\
5,4 \\
6,3 \\
5,0 \\
6,0\end{array}$ & $\begin{array}{r}9,8 \\
11,1 \\
9,8 \\
9,3 \\
13,2 \\
8,4 \\
9,9 \\
8,7 \\
12,2 \\
11,3 \\
10,8 \\
8,8 \\
7,3\end{array}$ & $\begin{array}{l}19,9 \\
20,3 \\
20,0 \\
21,1 \\
15,7 \\
22,9 \\
19,5 \\
19,4 \\
19,8 \\
20,7 \\
16,9 \\
21,4 \\
24,3\end{array}$ & $\begin{array}{l}39 \\
43 \\
41 \\
43 \\
43 \\
41 \\
44 \\
41 \\
42 \\
42 \\
45 \\
42 \\
39\end{array}$ \\
\hline G3 & $\begin{array}{l}\text { BRA } 284297 \text { CIAT G } 18649 \\
\text { MA } 534620 \text { - Novo Jalo } \\
\text { SEA } 7 \\
\text { G } 2227 \\
\text { Rico V, de Minas Gerais } \\
\text { BRA } 283291 \text { CIAT G } 18574 \\
\text { Coco blanchi } \\
\text { GORDO } \\
\text { BAT } 304 \\
\text { RAB } 94 \text { Vermelho } 2157 \\
\text { G } 14378 \\
\text { CARIOCA } \\
\text { G } 3566 \\
\text { PRETO COMUM } \\
\text { SEA 9 } \\
\text { G } 3474\end{array}$ & $\begin{array}{l}2042 \\
2022 \\
2024 \\
2027 \\
1997 \\
2000 \\
1945 \\
1942 \\
1938 \\
1922 \\
1971 \\
1952 \\
1960 \\
1879 \\
1890 \\
1892 \\
\end{array}$ & 1963 c & $\begin{array}{l}2208 \\
1530 \\
1398 \\
1825 \\
1661 \\
1744 \\
1456 \\
1313 \\
1537 \\
1651 \\
1429 \\
1580 \\
1736 \\
1432 \\
1351 \\
1568 \\
\end{array}$ & $\begin{array}{l}1876 \\
2514 \\
2651 \\
2228 \\
2333 \\
2256 \\
2434 \\
2571 \\
2340 \\
2194 \\
2513 \\
2324 \\
2183 \\
2327 \\
2429 \\
2216 \\
\end{array}$ & $\begin{array}{l}20,95 \\
38,48 \\
28,48 \\
24,61 \\
17,53 \\
21,18 \\
20,26 \\
40,98 \\
21,10 \\
20,85 \\
18,85 \\
22,07 \\
20,55 \\
22,77 \\
25,15 \\
17,09 \\
\end{array}$ & $\begin{array}{l}5,0 \\
3,7 \\
4,5 \\
7,2 \\
6,5 \\
5,7 \\
7,0 \\
3,5 \\
6,4 \\
5,9 \\
5,4 \\
5,8 \\
5,4 \\
5,7 \\
4,8 \\
4,9\end{array}$ & $\begin{array}{r}15,6 \\
12,8 \\
11,9 \\
8,8 \\
7,5 \\
10,8 \\
9,6 \\
8,9 \\
8,1 \\
9,2 \\
12,2 \\
10,9 \\
11,9 \\
9,9 \\
14,6 \\
11,0 \\
\end{array}$ & $\begin{array}{l}17,3 \\
15,2 \\
16,3 \\
17,9 \\
19,9 \\
19,6 \\
19,8 \\
16,8 \\
21,8 \\
24,2 \\
22,6 \\
18,7 \\
23,3 \\
17,1 \\
14,3 \\
22,0\end{array}$ & $\begin{array}{l}45 \\
38 \\
40 \\
42 \\
44 \\
46 \\
45 \\
38 \\
39 \\
41 \\
45 \\
44 \\
42 \\
44 \\
39 \\
40\end{array}$ \\
\hline G4 & $\begin{array}{l}\text { BAT } 1203 \\
\text { EMP } 86 \\
\text { Pirata } 1 \\
\text { G } 2475 \\
\text { Brasil } 0001 \\
\text { FE } 732007 \text { - Xamego } \\
\text { G } 4489 \\
\text { FFT } 85 \text { - } 75 \text { - Porto Real } \\
\text { G } 2359\end{array}$ & $\begin{array}{l}1506 \\
1750 \\
1768 \\
1781 \\
1709 \\
1804 \\
1815 \\
1815 \\
1837\end{array}$ & $1754 d$ & $\begin{array}{l}1220 \\
1287 \\
1351 \\
1521 \\
1422 \\
1503 \\
1599 \\
1699 \\
1714\end{array}$ & $\begin{array}{l}1791 \\
2213 \\
2186 \\
2040 \\
1997 \\
2106 \\
2031 \\
1932 \\
1960\end{array}$ & $\begin{array}{l}24,74 \\
17,88 \\
22,58 \\
21,35 \\
19,30 \\
18,90 \\
19,93 \\
23,79 \\
18,44\end{array}$ & $\begin{array}{l}5,9 \\
5,3 \\
5,5 \\
5,4 \\
6,3 \\
6,0 \\
5,5 \\
5,1 \\
5,3\end{array}$ & $\begin{array}{r}8,0 \\
9,9 \\
11,7 \\
7,9 \\
6,8 \\
10,3 \\
12,6 \\
10,9 \\
12,4\end{array}$ & $\begin{array}{l}18,0 \\
21,7 \\
14,6 \\
21,7 \\
21,3 \\
17,7 \\
18,9 \\
17,8 \\
21,1\end{array}$ & $\begin{array}{l}42 \\
42 \\
46 \\
43 \\
46 \\
43 \\
43 \\
41 \\
44\end{array}$ \\
\hline & Médias & 2084 & & 1647 & 2522 & 22,71 & 5,6 & 10,6 & 19,5 & 42 \\
\hline
\end{tabular}

${ }^{1}$ Médias seguidas de mesma letra na coluna não diferem significativamente entre si (teste t $5 \%$ ) ${ }^{2}$ das - dias após a semeadura

comum responde à deficiência hídrica pela redução do período de enchimento de grãos. Rosales-Serna et al. (2004) constataram que sob deficiência hídrica cultivares tolerantes apresentaram redução no número de dias para maturação; entretanto, Terán \& Singh (2002) observaram similaridade na maturação fisiológica entre genótipos com diferentes níveis de tolerância a esse estresse abiótico.
A não observação de correlação entre a produtividade com e sem deficiência hídrica e a data de floração neste trabalho, pode ser explicada pela altas temperaturas registradas durante o desenvolvimento das plantas (Figura 1), as quais reduziram o ciclo e moderaram o efeito da deficiência hídrica sobre o prolongamento do período vegetativo da planta. A alta temperatura, por também ocasionar o abortamento de flores e 
Tabela 3. Resumo da análise de regressão multivariada dos agrupamentos, segundo o método de $\mathrm{W}$ ard, considerando-se os valores médios das produtividades observadas em condições com e sem deficiência hídrica

\begin{tabular}{lrcc}
\hline \multirow{2}{*}{ FV } & \multirow{2}{*}{ G.L. } & \multicolumn{2}{c}{ Produtividade $\left(\mathbf{k g ~ h a}^{-1}\right)$} \\
\cline { 3 - 4 } & & Com deficiência hídrica & Sem deficiência hídrica \\
Grupo & 3 & $258.207,75^{* *}$ & $875.554,98^{* *}$ \\
Erro & 45 & $1.288,65$ & $5.031,61$ \\
CV (\%) & \multicolumn{3}{c}{3,40} \\
\hline ** significativo a 1\% de probabilidade pelo teste $\mathrm{F}$
\end{tabular}

vagens (Didonet \& Vitória, 2006), agrava o efeito da deficiência hídrica, que tem efeito similar sobre esses componentes de produtividade.

Verificou-se que, entre os componentes de produtividade, o número de vagens planta ${ }^{-1}$ foi o que mais influenciou na produtividade dos genótipos sob deficiência hídrica $(\mathrm{r}=-0,413$, p $\leq 0,003$ ); ele foi responsável, nesta condição hídrica, por $22,73 \%$ da variabilidade da produtividade e cada unidade da variável induziu ao aumento de $46 \mathrm{~kg} \mathrm{ha}^{-1}$ na produtividade do feijoeiro comum sob deficiência hídrica (Figura 2).

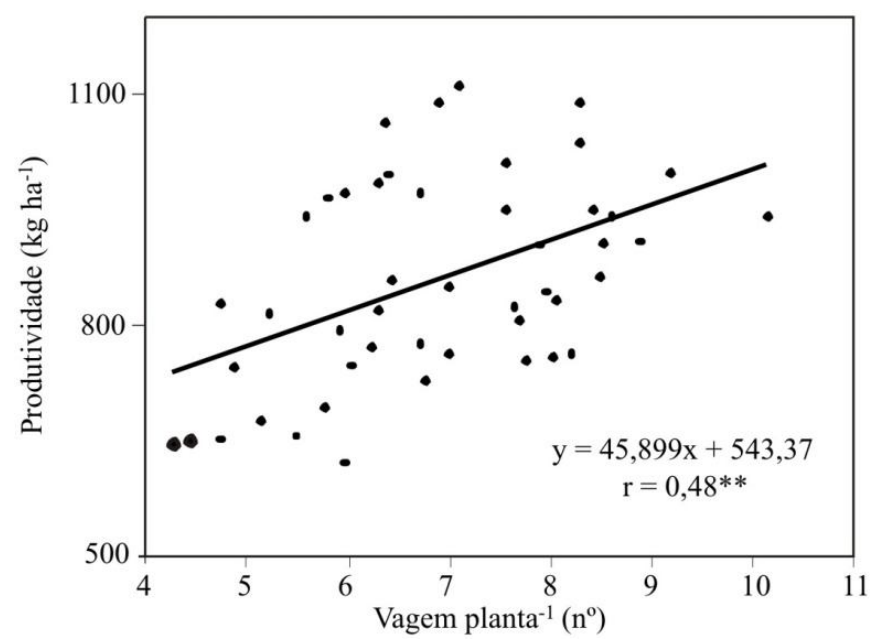

Figura 2. Efeito do número de grãos vagem ${ }^{-1}$ sobre a produtividade em condições de deficiência hídrica, Porangatu, G O

Ramirez-Vallejo \& Kelly (1998) também observaram que o número de vagens e de sementes representa os componentes de produtividade com maior resposta ao estado hídrico das plantas enquanto o tamanho das sementes foi mais estável. Lizana et al. (2006) acrescentam que a taxa de abscisão dos órgãos reprodutivos do feijoeiro comum foi consistente com o comportamento divergente intervarietal para tolerância à deficiência hídrica dessa cultura, ao lado do que, os genótipos mais tolerantes apresentaram plasticidade a nível de condutância estomática, taxa fotossintética, síntese de ácido abscísico e resistência à fotoinibição.

Verificou-se, ainda, que a produtividade dos genótipos em condições de deficiência hídrica diminuiu com o aumento da temperatura das folhas e que a cada grau de aumento resultou em $20 \mathrm{~kg} \mathrm{ha}^{-1}$ de redução na produtividade dos genótipos. Portanto, os genótipos que apresentavam temperatura das folhas mais baixas produziram melhor em razão de apresentarem também melhor estado hídrico (Figura 3A). O melhor estado hídrico pode estar associado tanto a mecanismos de contenção excessiva de perda de água como de melhor eficiência na absorção de água. Muñoz-Perea et al. (2007), em condições de deficiência hídrica severa, verificaram diferenças entre cultivares de feijoeiro quanto a eficiência de uso da água variando de 1,5 a 4,4 $\mathrm{kg} \mathrm{ha}^{-1} \mathrm{~mm}^{-1}$. Segundo Ludlow \& Muchow (1990), as características fenotípicas próprias para as condições específicas de suprimento de água determinam a melhor adaptação das plantas aos diferentes níveis de deficiência hídrica.
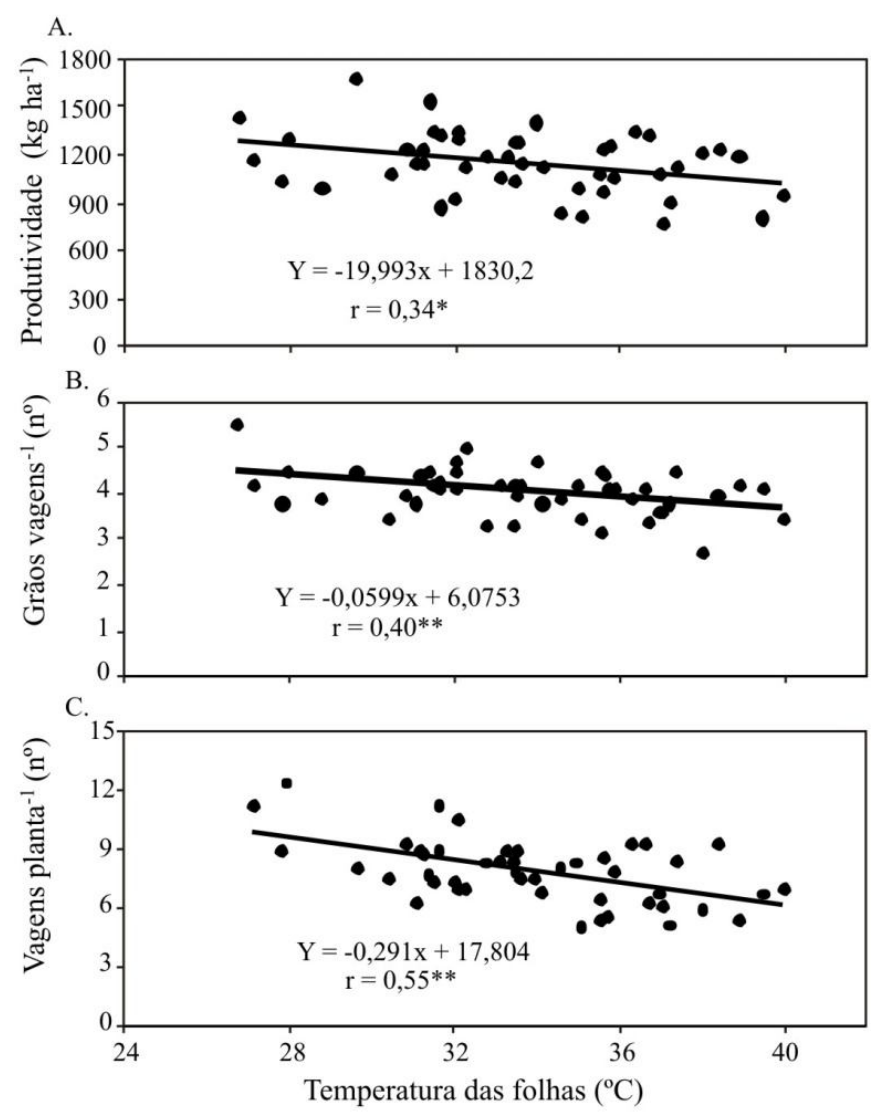

Figura 3. Relação entre a temperatura das fol has com produtividade $(A)$, número de grãos vagem ${ }^{-1}(B)$ e número de vagens planta ${ }^{-1}$ (C) sob deficiência hídrica durante 2006, Porangatu, G O

As características radiculares, segundo White \& Castillo (1989), são de importância primária na determinação do estado hídrico do feijoeiro comum. Ehleringer et al. (1991) acrescentam que a eficiência na transpiração pode ser determinada pelo movimento heliotrópico das folhas dessa cultura. Lizana et al. (2006) também observaram sensibilidade heliotrópica foliar do feijoeiro comum ao déficit hídrico; entretanto, não constataram diferença entre os genótipos com divergência para tolerância à deficiência hídrica.

A termometria infravermelha pode inferir no estado hídrico da planta e discriminar genótipos fisiologicamente mais adaptados à deficiência hídrica (Bascur et al., 1985). Oliveira et al. (2005) constataram que a temperatura da folha do feijoeiro apresentou estreita relação com a resistência estomática. 
Conforme Guimarães et al. (2006), o coeficiente de correlação da temperatura do dossel com o estado hídrico das plantas, medido pelo potencial da água nas folhas, foi de $-0,8280$ ( $p<$ 0,0001 ) sugerindo que a termometria de infravermelho é eficiente na inferência do estado hídrico da planta e, portanto, útil para discriminar genótipos em programas de tolerância à deficiência hídrica.

Observou-se que tanto o número de grãos vagem ${ }^{-1}$ como o de vagens planta ${ }^{-1}$ também foram reduzidos com o aumento da temperatura das folhas, conforme os dados de 2006 (Figuras $3 \mathrm{~B}$ e $3 \mathrm{C}$ ). Acrescenta-se que o número de vagens planta ${ }^{-1}$ foi mais intensamente afetado que o de grãos vagem ${ }^{-1}$, inferindose que a deficiência hídrica atua com mais intensidade sobre a abscisão de flores e vagens que sobre a esterilidade do grão de pólen, a qual determina menor número de grãos vagem ${ }^{-1}$. Resultados similares foram observados nos experimentos conduzidos em 2007.

\section{CONCLUSÕES}

1. Os genótipos BRA 130583 CIAT G 6490 e FT 84 - 292 são produtivos tanto na ausência como na presença de deficiência hídrica.

2. Os genótipos BRA283983 CIAT G 6492, BRA 129721 CIAT G 6896 e G 983 são produtivos na ausência de deficiência hídrica porém são mais sensíveis a esse estresse.

3. O número de vagens planta-1 é o componente agronômico mais sensível ao estado hídrico do feijoeiro comum.

4. O número de grãos vagem ${ }^{-1}$ e o de vagens planta ${ }^{-1}$ foram reduzidos com o aumento da temperatura das folhas mas este último com mais intensidade.

\section{Agradecimentos}

Aos auxiliares Neuza Maria Prado Rios e Ramatis Justino da Silva, pelo auxílio na condução desta pesquisa, e ao Projeto Generation, pelo apoio financeiro.

\section{LITERATURA CITADA}

Bascur, G.; Oliva, M. A.; Laing, D. Termometria infrarroja en selección de genotipos de frijol (Phaseolus vulgaris L.) resistentes a la sequía. I. Bases fisiológicas. Turrialba, v.35, p.43-47, 1985.

CIAT - Centro Internacional de Agricultura Tropical. Bean program: Annual report 1984. Cali: CIAT, 1985. p.92-96. Working Document, 7

Didonet, A. D. Ecofisiologia e rendimento potencial do feijoeiro. In: Peloso, M. J. Del; Melo, L. C. (ed.) Potencial de rendimento da cultura do feijoeiro comum. Santo Antônio de Goiás: Embrapa Arroz e Feijão, 2005. Cap.1, p.9-37.

Didonet, A. D.; Vitória, T. B. Resposta do feijoeiro comum ao estresse térmico aplicado em diferentes estágios fenológicos. Pesquisa Agropecuária Tropical, v.36, p.199$204,2006$.
Ehleringer, J. R.; Klassen, S.; Clayton, C.; Sherrill, D.; FullerHolbrook, M.; Fu, Q.; Cooper, T. A. Carbon isotope discrimination and transpiration efficiency in common bean. Crop Science, v.31, p.1611-1615, 1991.

Guimarães, C. M.; Brunini, O.; Stone, L. F. Adaptação do feijoeiro (Phaseolus vulgaris L.) à seca. I. Densidade e eficiência radicular. Pesquisa Agropecuária Brasileira, v.31, p.393-399, 1996.

Guimarães, C. M.; Stone, L. F.; Brunini, O. Adaptação do feijoeiro comum (Phaseolus vulgaris L.) à seca. Revista Brasileira de Engenharia Agrícola e Ambiental, v.10, p.7075, 2006.

Guimarães, C. M.; Zimmermann, M.J. Deficiência hídrica em feijão. In: Reunion de Trabajo sobre Mejoramiento en Frijol en Brasil con Enfasis en Tolerancia a Sequia, 1, 1985, Cali. Anais... Cali: CIAT, 1985. p.15-28.

Hsiao, T. C. Measurements of plant water status. In: Stewart, B.A.; Nielsen, D.R. (ed.) Irrigation of agricultural crops. New York: American Society of Agronomy, 1990. p.244280.

Jongdee, B.; Pantuwan, G.; Fukai, S.; Fischer, K. Improving drought tolerance in rainfed lowland rice: an example from Thailand. Agricultural Water Management, v.80, p.225-240, 2006.

Kramer, P. J.; Boyers, J. S. Evolution and agriculture. In: Kramer, P. J.; Boyers, J. S. (ed.) Water relations of plants and soils. San Diego: Academic Press, 1995. p.377-404.

Lizana, C.; Wentworth, M.; Martinez, J. P.; Villegas, D.; Meneses, R.; Murchie, E. H.; Pastenes, C.; Lercari, B.; Vernieri, P.; Horton, P.; Pinto, M. Differential adaptation of two varieties of common bean to abiotic stress. I. Effects of drought on yield and photosynthesis. Journal of Experimental Botany, v.57, p.685-697, 2006.

Ludlow, M. M.; Muchow, R. C. A critical evaluation of traits for improving crop yields in water-limited environments. Advances in Agronomy, v.43, p.107-153, 1990.

Muñoz-Perea, C. G.; Allen, R. G.; Westermann, D. T.; Wright, J. L.; Singh, S. P. Water use efficiency among dry bean landraces and cultivars in drought-stressed and nonstressed environments. Euphytica, v.155, p.393-402, 2007.

Muñoz-Perea, C. G.; Terán, H.; Allen, R. G.; Wright, J. L.; Westermann, D. T.; Singh, S.P. Selection for drought resistance in dry bean landraces and cultivars. Crop Science, v.46, p.2111-2120, 2006.

Oliveira, A. D. de; Fernandes, E. J.; Rodrigues, T. de J. D. Condutância estomática como indicador de estresse hídrico em feijão. Engenharia Agrícola, v.25, p.86-95, 2005.

Pimentel, C.; Perez, A. J. de La C. Estabelecimento de parâmetros para avaliação de tolerância à seca, em genótipos de feijoeiro. Pesquisa Agropecuária Brasileira, v.35, p.31-39, 2000.

Ramirez-Vallejo, P.; Kelly, J. D. Traits related to drought resistance in common bean. Euphytica, v.99, p.127-136, 1998.

Rosales-Serna, R.; Kohashi-Shibata, J.; Acosta-Gallegos, J.A.; Trejo-Lopez, C.; Ortiz-Cereceres, J.; Kelly, J.D. Biomass distribution, maturity acceleration and yield in droughtstressed common bean cultivars. Field Crop Research, v.85, p.203-211, 2004. 
Rosielle, A.A.; Hamblin, J. Theoretical aspects for yield in stress and non-stress environments. Crop Science, v.21, p.943946, 1981.

Schneider, K.A.; Rosales-Serna, R.; Ibarra-Perez, F.; CazaresEnriquez, B.; Acosta-Gallegos, J. A.; Ramirez-Vallejo, P.; Wassimi, N.; Kelly, J.D. Improving common bean performance under drought stress. Crop Science, v.37, p.4350, 1997.

Silveira, P. M. da; Stone, L.F. Manejo da irrigação do feijoeiro: uso do tensiômetro e avaliação do desempenho do pivô central. Brasília: Embrapa-SPI, 1994. 46p. Embrapa-CNPAF. Documentos, 27

Singh, S. P. Selection for water-stress tolerance in interracial populations of common bean. Crop Science, v.35, p.118124, 1995.
Steinmetz, S., Reyniers, F. N.; Forest, F. Caracterização do regime pluviométrico e do balanço hídrico do arroz de sequeiro em distintas regiões produtoras do Brasil: Síntese e interpretação dos resultados. Goiânia: Embrapa CNPAF, 1988. v.1. 66p. Documentos, 23

Terán, H.; Singh, S. P. Comparison of sources and lines selected for drought resistance in common bean. Crop Science, v.42, p.64-70, 2002.

Ward, J. H. Hierarchical grouping to optimize an objective function. Journal of the American Statistical Association, v.58, p.236-244, 1963.

White, J. W.; Castillo, J. A. Relative effect of root and shoot genotypes and yield on common bean under drought stress. Crop Science, v.29, p.360-362, 1989.

White, J. W.; Sponchiado, B. N. Tolerancia del frijol a la sequía: interrogantes y algunas respuestas. Hojas de Frijol para América Latina, v.7, p.1-3, 7, 1985. 